\title{
Adenocarcinoma of the pyloric antrum with extensive squamous differentiation
}

\author{
K. J. DONALD \\ From the Department of Pathology, Royal Brisbane Hospital, Brisbane, Australia
}

SYNOPSIS A case of adenocarcinoma of the pyloric antrum with extensive squamous differentiation is described. Unusually obvious areas of transition between malignant cell types are present and the implications of these are briefly discussed.

Adenocarcinoma of the pyloric region of the stomach with squamous differentiation is a rare tumour. Wood (1943) reviewed reports of several thousand cases of gastric carcinoma and found only seven examples, to which he added two. Nagel (1956) found 10 cases of this tumour described in the literature between 1943 and 1956 and added a further case. The present paper describes an example with unusually obvious areas of transition.

\section{CASE HISTORY}

A 69-year-old man, stated to be a chronic alcoholic, died 36 hours after admission to hospital. He had suffered from 'abdominal colic' for 10 days. The blood urea level on the day before death was $394 \mathrm{mg} . \%$.

\section{MACROSCOPIC NECROPSY FINDINGS}

The retroperitoneal tissue was diffusely fibrous and this process had obstructed both ureters, presumably causing death from uraemia. There was an ulcerated tumour $3 \mathrm{~cm}$. in diameter on the posterior aspect of the pyloric antrum. It extended principally outside the stomach and had displaced the head of the pancreas but had not invaded that organ. No other primary neoplasm was found.

\section{HISTOPATHOLOGY}

The primary tumour showed areas of well-differentiated adenocarcinoma and also extensive areas of squamous differentiation. The tissue around the central ulcer was mainly squamous in type (Fig. 1) and was surrounded by a zone of transition which intervened between the squamous and the adenocarcinomatous areas. The deeper portions of the tumour were predominantly adenocarcinoma (Fig.

Received for publication 9 August 1966.
2). Transitions between malignant cuboidal or columnar cells and malignant squamous epithelium were frequently present within a single acinus (Fig. 3).

The general arrangement of the tissues of the primary is represented diagrammatically in Fig. 4. No area was entirely devoid of squamous differentiation. Mitoses were common in all cell types. Signet ring cells were also plentiful. Multiple points of origin of early invasive adenocarcinoma were present in the mucosa adjacent to the ulcer, but no squamous epithelium was found in a large number of sections taken from areas bordering the lesion. Throughout the primary tumour there was a dense cellular fibrous tissue stroma.

Small secondary deposits of adenocarcinoma were present in both suprarenals, both kidneys, the spleen, and the mesenteric lymph glands. The retroperitoneal lymph glands were involved over a large area and radial extension from these was present along lymphatics, for considerable distances, accompanied by prominent fibrous tissue formation. Some of the metastases were less well-differentiated than the primary, and in places consisted of sheets of anaplastic cells. Abundant fibrous tissue stroma resembling that of the primary tumour was prominent in all metastases. No squamous epithelium was present in slides from $\mathbf{4 0}$ blocks taken from secondary deposits, but heaping up of the epithelium was often observed in acinar structures.

\section{DISCUSSION}

This tumour is an example of an adenocarcinoma with squamous differentiation arising in an area where squamous epithelium does not normally occur. Such tumours are more commonly found in areas where squamous metaplasia is frequent or where squamous and glandular surfaces adjoin. 


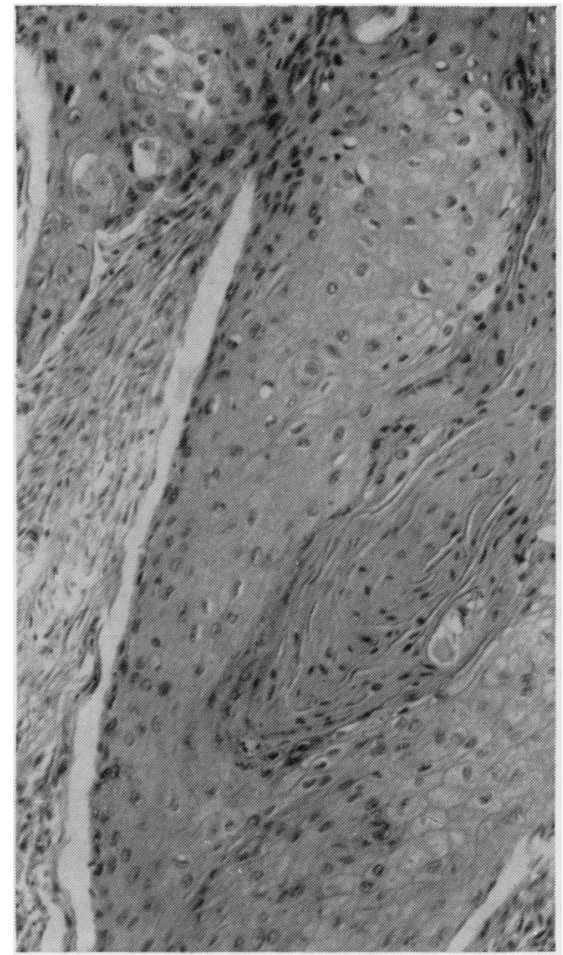

FIG. 1.

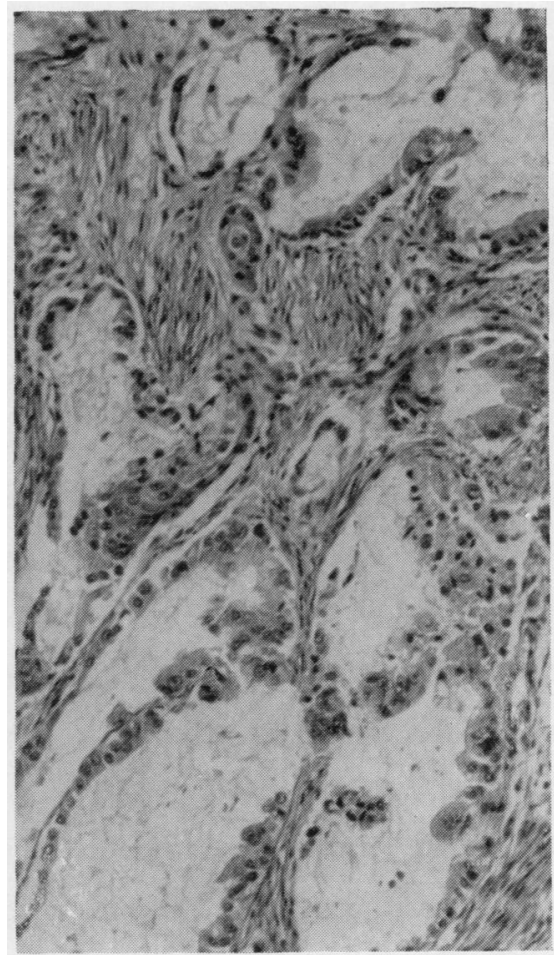

FIG. 1. Section from tumour of the pyloric antrum showing an area of squamous carcinoma. Haematoxylin and eosin $\times 120$.

FIG. 2. Section from tumour of the pyloric antrum showing an area of adenocarcinoma.

Haematoxylin and eosin $\times 120$.

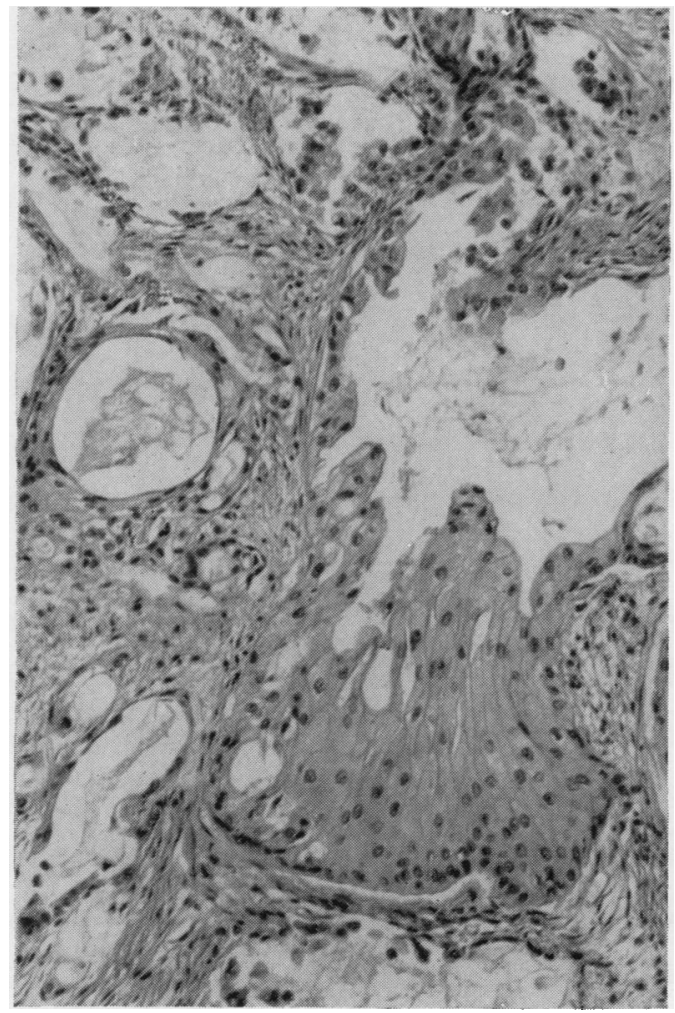

FIG. 2.

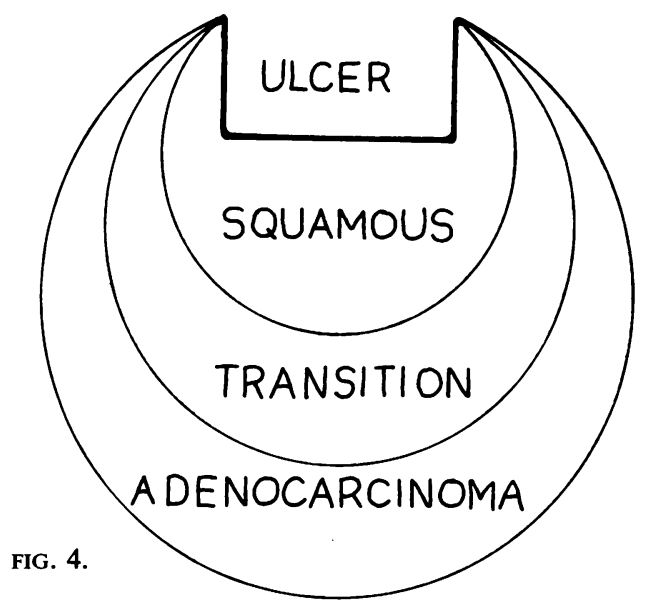

FIG. 3. Section from tumour of the pyloric antrum showing an area of transition in an acinus between adenocarcinoma and squamous carcinoma. Haematoxylin and eosin $\times 120$.

FIG. 4. Schematic arrangement of tissues in the primary tumour.

FIG. 3. 
Wood (1943) discussed the rarity of squamous metaplasia in the stomach, and reviewed many unsuccessful attempts to produce this change in experimental animals. He concluded that antecedent squamous metaplasia is not necessary for this tumour to occur and suggested that undifferentiated basal cells in the gastric mucosa might give rise to these neoplasms.

In the present case extensive examination of the stomach has failed to reveal any squamous epithelium away from the primary tumour, although multiple areas of adenocarcinoma in the mucosa of the stomach near the lesion have been observed. The intimate association of the two tissue types in the tumour, and transitions of cell types that have been demonstrated within a single acinar structure, suggest that the only likely explanation of these findings is a dichotomy of differentiation of the tumour cells, and not an area in which there was previous squamous metaplasia or undifferentiated basal cells.

This material adds evidence to the opinion that there exists a potentiality in normal and neoplastic cells to undergo changes of differentiation, a subject of long standing controversy. Recent findings in cell biochemistry suggest that all the information in the D.N.A. of the zygote is retained by its descendant cells, and that a continuing process of selective control of genetic expression, rather than a finished event in the past, maintains the normal functional and structural characteristics of a particular cell. Changes in this process of selective control may be important in the response of cells to environment and perhaps in neoplasia. Some support for these suggestions may be found in the distribution of the squamous tissue in the present tumour and the absence of such differentiation in the metastases. In some previously reported examples of these neoplasms squamous epithelium has been described in both primary and secondary sites (Wood, 1943).

I would like to thank Dr. J. Nye, senior physician, Royal Brisbane Hospital, under whose care the patient was admitted, Dr. A. D. D. Pye for permission to use the hospital records, and Mr. B. Stewart for the photography.

\section{REFERENCES}

Cook, C. B., and Klickstein, G. D. (1958). Arch. Path., 65, 681.

Nagel, L. R. (1956). Ibid., 62, 37.

Wood, D. A. (1943). Ibid., 36, 177. 